\title{
Normas para los colaboradores
}

\section{NOTAS DE INTERÉS}

- Se exhorta a los investigadores a cumplir con las normas de publicación descritas al momento de postular sus manuscritos. El no cumplimiento de estas pautas impedirá que sea considerada la investigación por parte del comité editor.

- $\quad$ RCS NO recibe investigaciones en inglés. A partir del año 2022, el comité editor, previa revisión de los artículos a publicarse en un numero de acuerdo al impacto y relevancia temática, selecciona una o dos investigaciones para posible publicación del manuscrito en la revista en inglés. Aclaratoria: una vez recibida una investigación post arbitraje y validando el fiel cumplimento de las observaciones, si las hubiese del proceso, se realiza un contacto con el investigador indicado (su interés o no, sobre realizar la publicación de su investigación en inglés). Por lo que el investigador que se encuentre de acuerdo realiza la traducción de ese manuscrito final para publicación.

- Se destaca que el proceso de evaluación puede ser menor o mayor, de acuerdo con la disponibilidad de los árbitros, así como otros factores que pueden influir en el proceso.

- La postulación de un manuscrito a la RCS, no obliga al comité editorial ni a su editor a garantizar o realizar la publicación del documento

- $\quad$ El comité de RCS se reserva el derecho de rechazar estudios cuya: solidez teórica y conceptual, adecuación y familiaridad de la bibliografía, rigor metodológico, calidad de análisis, discusión de resultados, validez y pertinencia sea deficiente y escasa.

- El comité editorial se reserva el derecho de seleccionar aquellos estudios métricos cuyo potencial sea, demostrado, justificado y sustentado. Destacando que se estipula la publicación previo proceso de arbitraje de un número reducido de estudios métricos por número.

\section{ASPECTOS FORMALES}

1. La Revista Ciencias Sociales, de la Facultad de Ciencias Económicas y Sociales de la Universidad del Zulia, Maracaibo-Venezuela, considerará para su publicación trabajos inéditos en las áreas de Economía, Sociología, Administración y Contaduría, producto de investigaciones tales como: artículos científicos, ensayos, comunicaciones rápidas escritas por autores de reconocida trayectoria y revisiones bibliográficas cuya finalidad sea contribuir al avance del conocimiento. Los trabajos escritos en español, que no hayan sido propuestos simultáneamente en otras revistas ni alojado en algún sitio o portal web, 


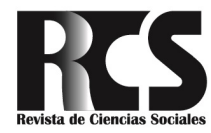

asimismo se reserva el derecho de hacer las modificaciones de forma que el Comité Editor considere necesarias, una vez publicada la investigación, el autor NO pierde sus derechos sobre el artículo.

2. Organización de secciones y sub-secciones definidas (obligatorio)

Los artículos deben contener: Introducción (incluyendo la metodología, si es breve, sino en sección aparte) que les motiva y justifica el realizar esa investigación, plantear el objetivo del estudio, Fundamentación teórica: diferentes puntos y sub-puntos (cada apartado debe tener numeración consecutiva, no debe haber grandes diferencias de tamaño entre los puntos, los títulos se escribirán en negritas, a la izquierda y en minúscula, solo la inicial de la primera palabra en mayúscula), Metodo, Resultados y discusión, Conclusiones, Notas (si aplica, pocas) y Referencias bibliográficas (citadas en el texto, ajustada a normas APA 7ma edición).

La RCS considera las siguientes modalidades de manuscritos publicables:

- Artículo: es una investigación puntual de carácter monográfico, preferiblemente resultado parcial o final de una investigación donde se destaca la argumentación reflexiva y crítica sobre problemas teóricos y/o prácticos, metodológicos y/o epistemológicos del tema y el área de estudio explorado. La extensión mínima será de 15 páginas y no deberá exceder de 25 páginas incluyendo las referencias bibliográficas.

Para las investigaciones de revisión sistemática de literatura, el número mínimo de referencias bibliográficas será de 50, estas investigaciones deberán ser procedentes de: Arts and Humanities Citation Index, Emerging Sources Citation Index, Science Citation Index Expanded, Scopus, Social Sciences Citation Index. De no cumplir con este elemento no serán considerados para proceso de evaluación y publicación.

- Ensayo: es una interpretación original y personal, prescinde del rigor de la formalidad de una monografía, le permite a un investigador consolidado presentar sus posturas teóricas sobre la actualidad y trascendencia de las formas de pensamiento o los paradigmas, en los que se desarrolla su disciplina y temas afines. Su extensión no deberá exceder las 15 páginas y se deben asumir las normas editoriales.

- Reseña bibliográfica: es una colaboración que pone al día la actualidad bibliográfica, se recogen los principales resultados de las investigaciones nacionales e internacionales en forma de libro individual o colectivo. Resalta el análisis crítico sobre los diversos niveles (teóricos, metodológicos, epistémicos, políticos, sociales, entre otros) donde se pueden demostrar el impacto de las investigaciones. Su extensión no deberá exceder las 5 páginas y se deben asumir las normas editoriales.

- Carta al Editor: opiniones sobre tópicos nuevos o problemas coyunturales en el campo de las ciencias sociales. Su extensión no deberá exceder las 10 páginas y se deben asumir las normas editoriales.

- Comunicaciones Rápidas: para dar a conocer el derecho de propiedad intelectual.

3. La Revista de Ciencias Sociales (RCS) de carácter trimestral cuyos periodos de publicación se establecen en los meses enero-marzo, abril-junio, julio-septiembre y octubre-diciembre. La convocatoria para recepción de trabajos estará abierta durante todo el año.

4. Esta revista proporciona un acceso abierto a su contenido, basado en el principio de que ofrecer al público un acceso libre a las investigaciones ayuda a un mayor intercambio global del conocimiento. A través de la plataforma de revistas científicas pueden ser consultas, visualizadas y descargadas los 


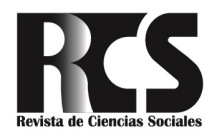

diferentes volúmenes y números publicados bajo estándares de acceso abierto.

5. Esta obra está bajo la licencia:

Creative Commons Reconocimiento-NoComercial-CompartirIgual 4.0 Internacional (CC BYNC-SA 4.0) https://creativecommons.org/licenses/by-nc-sa/4.0/

6. RCS se adhiere a las políticas de buenas prácticas establecidas por COPE https://publicationethics. org/

7. Las propuestas para publicación no tienen ningún costo en la revista. La Revista de Ciencias Sociales NO establece costo, ni cobros por procesamiento, publicación y distribución de artículos.

8. Las propuestas deben enviarse al e-mail: rcs_luz@yahoo.com, en archivo microsoft Word editable, adicionalmente debe remitirse una breve reseña curricular (incluyendo títulos académicos, filiación institucional, correo y orcid) y una comunicación firmada certificando el carácter inédito de la obra y cediendo los derechos de publicación. Por política editorial esta revista no publica en un mismo año productos de investigaciones de un mismo autor o coautor. Los trabajos serán recibidos para iniciar el proceso de evaluación previa revisión del comité editorial, considerando la relevancia del tema y pertinencia, acorde a las áreas de la revista, originalidad y cumplimiento de estas normas.

9. Posteriormente, los trabajos serán evaluados de acuerdo al sistema doble ciego, tomando en cuenta los siguientes criterios: originalidad, novedad, actualidad, aportes al conocimiento, claridad y coherencia del discurso, adecuada organización interna y elaboración del resumen, pertinencia del título y calidad de las referencias bibliográficas. Previo proceso de postulación de una investigación se utiliza un sistema en línea para la detección de plagio por parte del comité editorial luego de esta revisión se remite el manuscrito al árbitro correspondiente.

10. Los autores deberán consignar de nuevo a la RCS, en un lapso no mayor de 15 días hábiles a partir de la fecha de notificación por parte del editor, la versión corregida según observaciones de los árbitros.

11. El proceso de evaluación y aceptación de las investigaciones es de 30 a 45 días aproximadamente, tomando como elemento de referencia la recepción de la investigación, evaluación previa del comité, selección de los árbitros y el tiempo de respuesta de los evaluadores. Una vez obtenido el dictamen correspondiente sobre la investigación es notificado el autor sobre los resultados obtenidos.

Se destaca que el proceso de evaluación puede ser menor o mayor, de acuerdo con la disponibilidad de los árbitros, así como otros factores que pueden influir en el proceso.

12. La recepción de artículos se realizará durante todo el año. El comité editorial se reserva el derecho de cerrar convocatorias cuando considere adecuado a fin de cumplir con la respuesta oportuna a los investigadores.

\section{ASPECTOS ESTRUCTURALES DE LAS INVESTIGACIONES}

13. Los trabajos deben ser presentados en formato Microsoft Word, editable, interlineado, sencillo, solo el resumen y abstract. A partir de la introducción doble espacio, papel, tamaño carta, letra Arial 12 , con márgenes $2,5 \mathrm{~cm}$ de cada lado, con numeración consecutiva; incluyendo la portada, tablas e ilustraciones, notas y referencias bibliográficas.

14. Título: Debe ser corto, no mayor a 15 palabras explicativo y recoger la esencia del trabajo. Escrito en español e inglés. Evitar siglas y acrónimos. No debe iniciar con artículo gramatical, verbo o acción. 


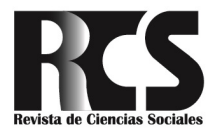

15. Autores: Indicar los nombres y apellidos completos. En pie de página, colocar títulos académicos, ente y/o institución de adscripción, correo electrónico y ORCID. Máximo cuatro (4) autores.

16. Resumen: En español con una extensión máxima de 200 palabras. Debe contener: Breve introducción, objetivo o propósito, método, resultados o principales hallazgos y conclusiones principales.

17. Palabras clave en español: las cuales describen el contenido del trabajo. Se utilizarán cinco (5) palabras clave, para su inclusión en los índices nacionales e internacionales (indización). Se presentarán al final del resumen.

18. Abstract: Traducción del resumen en el idioma inglés, precedido del título en el mismo idioma. Se recomienda asesoramiento de especialistas.

19. Keywords: Traducción de las palabras clave en el idioma inglés.

20. Organización de secciones y sub-secciones definida (obligatorio)

- Los artículos deben contener: Introducción (incluyendo la metodología, si es breve, sino en sección aparte) que les motiva y justifica el realizar esa investigación, plantear el objetivo del estudio, Fundamentación teórica: diferentes puntos y sub-puntos (cada apartado debe tener numeración consecutiva, no debe haber grandes diferencias de tamaño entre los puntos, los títulos se escribirán en negritas, a la izquierda y en minúscula, solo la inicial de la primera palabra en mayúscula), Método, Resultados y discusión, Conclusiones, Notas (si aplica, pocas) y Referencias bibliográficas (citadas en el texto, ajustada a normas APA 7ma edición).

21. Tablas (números), cuadros (palabras), cada una de estas representaciones debe identificarse consecutivamente con números arábigos $(1,2,3 \ldots)$, tener un encabezamiento específicamente descriptivo colocado en la parte superior, estar citadas en el texto, y las abreviaturas y símbolos explicados al pie de la tabla.

22. Figuras, gráficos, mapas, ilustraciones u otras representaciones gráficas, deben identificarse consecutivamente con números romanos $(I, I I, I I I \ldots)$ en cursiva, tener un encabezamiento específicamente descriptivo colocado en la parte inferior, estar citadas en el texto, y las abreviaturas y símbolos explicados al pie. Identificar en la parte inferior de todas las representaciones, la fuente o procedencia de la información. Asimismo, deben estar insertadas en el texto y en formato editable.

23. Los encabezamientos de cada sección se escribirán en negritas, a la izquierda y en minúscula.

24. Los símbolos matemáticos deben ser muy claros y legibles. Los sub-índices y supra-índices deben estar correctamente ubicados.

25. Bibliografía citada: Debe ser pertinente, actualizada y estar estrictamente referenciada en el texto.

a. La Bibliografía citada debe conservar el estilo APA. insertadas en el texto con énfasis en el autor: Santos (2019) afirma que...; basada en el texto (Santos, 2019). Cuando la referencia se hace textualmente, basada en el autor: Santos (2019) afirma: "Lo citado textual" (p.24). Basado en el texto: "lo citado textual" (Santos, 2019, p.24). Si la cita tiene más de 40 palabras se escriben aparte del texto, con sangría, sin comillas ni cursiva. Se sigue el estilo anterior dependiendo de si el énfasis es en el texto: se coloca aparte Lo citado textual. (Santos, 2019, p.24); o en el autor: Santos (2019) afirma que: aparte Lo citado textual. (p.24)

b. Según números de autores: Si son dos, sus apellidos van separados por “y”. De tres a cinco autores, la primera vez que se citan se indican los apellidos de todos. Posteriormente se cita solo el primero y se agrega et al, seguido de punto (et al.). Cuando son seis o más autores se cita el apellido del primero 


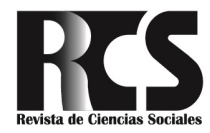

seguido de et al. desde la primera citación.

c. En el caso de que sea un autor corporativo se coloca el nombre de la organización en vez del apellido. La primera vez se cita el nombre completo y entre el paréntesis se indica la sigla. En adelante, se cita solamente con la sigla. Banco Central de Venezuela (BCV, 2019).

d. Cuando se realizan párrafos que amplían o explican lo desarrollado en el texto, estos se deben marcar con un índice (1) y ubicar después de las conclusiones y antes de las referencias bibliográficas con el título "Notas". Sólo colocar aquellas que sean estrictamente pertinentes para una comprensión exacta del trabajo.

e. Referencias bibliográficas: Todos los autores citados en el cuerpo de un texto o trabajo deben coincidir con la lista de referencias del final, nunca debe referenciarse un autor que no haya sido citado en el texto y viceversa. La lista de referencias se organiza en orden alfabético y cada una debe tener sangría francesa. Para la referenciación de números o volúmenes de alguna publicación es necesario usar números arábigos y no romanos.

- Libros: Apellido, A. A. (Año). Título. Ciudad, País: Editorial. (North, D. C. (2019). Instituciones. Cambio institucional y desempeño económico. D.F., México: Fondo de Cultura Económica). Con editor: Apellido, A. A. (Ed.). (Año). Título. Ciudad, País: Editorial. Libro en versión electrónica: Apellido, A. A. (Año). Título. Recuperado de http://www.Xxxxxx.xxx. Capítulo en Libro: Apellido, A. A., y Apellido, B. B. (Año). Título del capítulo o la entrada. En A. A. Apellido. (Ed.), Título del libro (pp. xx-xx). Ciudad, País: Editorial.

- Revistas Periódicas: Artículo impreso: Apellido, A. A. (Año). Título del artículo. Nombre de la revista, volumen(número), pp-pp. (Valecillos, H. (2019). Mercado de trabajo y redistribución del ingreso. Situación actual y perspectivas. Revista del Banco Central de Venezuela, 7(2), 73-112). Si el artículo tiene DOI, se coloca después de las páginas. Artículo online: igual al anterior y al final se coloca Recuperado de http://www.xxxxxx.xxx De dos a siete autores: Se listan todos los autores separados por coma y en el último se escribe "y". Apellido, A. A., Apellido, B. B., y Apellido, C. C. Ocho o más autores: Se listan los primeros seis autores, se colocan puntos suspensivos y se lista el último autor.

- Periódico: Apellido A. A. (Fecha). Título del artículo. Nombre del periódico, pp-pp. Impreso con autor: Manrique, J. (14 de noviembre de 2010). La bestia que se tragó Armero. El Espectador, pp. 1617. Sin autor: La bestia que se tragó Armero. (14 de noviembre de 2010). El Espectador, pp. 16-17. Online: Apellido, A. A. (Fecha). Título del artículo. Nombre del periódico. Recuperado de

- Informes: Nombre de la organización. (Año). Título del informe (Número de la publicación). Recuperado de http://www.xxxxxx.xxx (Ministerio de la Protección Social (1994). Informe cientifico de casos de fiebra amarilla en el departamento del Meta. Recuperado de http://www.minproteccionsocial. gov.co/

- Simposios y Conferencias: Autor, A., y Autor, A. (Fecha). Título de la ponencia. En A. Apellido del presidente del congreso (Presidencia), Título del simposio o congreso. Simposio o conferencia llevado a cabo en el congreso Nombre de la organización, Lugar. (Manrique, D., y Aponte, L. (Junio de 2011). Evolución en el estudio y conceptualización de la consciencia. En H. Castillo (Presidencia), El psicoanálisis en Latinoamérica. Simposio llevado a cobo en el XXXIII Congreso Iberoamericano de Psicología, Medellín, Colombia).

- Tesis y Trabajos de Grado: Autor, A., y Autor, A. (Año). Título de la tesis (Tesis de pregrado, maestría o doctoral). Nombre de la institución, Lugar. (Aponte, L, y Cardona, C. (2009). Educación ambiental 


\section{RCS}

y evaluación de la densidad poblacional para la conservación de los cóndores reintroducidos en el Parque Nacional Natural Los Nevados y su zona amortiguadora (Tesis de pregrado). Universidad de Caldas, Manizales, Colombia.

- Material Electrónico: Apellido, A. A. (Fecha). Título de la página. Lugar de publicación: Casa publicadora. dirección de donde se extrajo el documento (URL). (Argosy Medical Animation. (20072009). Visible body: Discover human anatomy. New York, EU.: Argosy Publishing. Recuperado de http://www.visiblebody.com 